\title{
Relationship of the Microstructure and Toughness of the Coarse Grain Heat-Affected Zone of TiNbV Microalloyed Steels Based on Electron Backscatter Diffraction Analysis
}

\author{
Han Yan, Di Zhao, Tongfu Qi, Xuesong Leng, and Kuijun Fu
}

\author{
Submitted: 10 March 2021 / Revised: 4 July 2021 / Accepted: 11 July 2021 / Published online: 7 October 2021
}

\begin{abstract}
The microstructure evolution and impact toughness of the coarse grain heat-affected zone (CGHAZ) of TiNbV microalloyed steels were investigated by using a thermal simulation test. The samples were treated with various simulated welding thermal cycles. The phase constituents and grain sizes were analyzed by using electron backscatter diffraction analysis. The microstructure of the CGHAZ of the treated samples consisted of ferrite, acicular ferrite, pearlite, and bainite. The samples have a higher impact toughness under a lower welding heat input. This is because the microstructure of the CGHAZ is dominated by the higher volume fraction of the high-angle grain boundaries of acicular ferrites. The presence of bainite and coarsening grains are two key factors deteriorating the toughness of the CGHAZ of TiNbV microalloyed steels. The volume fraction of bainite sharply increased as the welding heat input increased, leading to a decrease in the impact toughness of the CGHAZ. For a higher welding heat input, both the severe coarsening of the grain size and a higher bainite content would result in poor impact toughness.
\end{abstract}

Keywords EBSD analysis, HAZ, microalloyed steel, thermal simulation, welding thermal cycle

\section{Introduction}

High-strength low alloy steel (HSLA) has been widely applied to large-scale structures in engineering construction, such as shipbuilding, offshore structures, and oil storage where it has extensive requirements for welding technologies (Ref 1, 2). High heat input welding processes have been widely employed to minimize cost and improve production efficiency (Ref 3). However, high heat input welding tends to deteriorate the strength and toughness of the heat-affected zone (HAZ), which is an aspect of serious concern for the welding of high strength low alloy steels.

In comparison with traditional welding, high heat input welding requires a higher peak temperature and a longer cooling time, which will give rise to the obvious coarsening of

Han Yan, State Key Laboratory of Advanced Welding and Joining, Harbin Institute of Technology, Harbin 150001, People's Republic of China; and Department of Mechanical Engineering, The University of Sheffield, Sheffield S10 2TN, UK; Di Zhao and Tongfu Qi, State Key Laboratory of Advanced Welding and Joining, Harbin Institute of Technology, Harbin 150001, People's Republic of China; Xuesong Leng, School of Materials Science and Engineering, Harbin Institute of Technology (Shenzhen), Shenzhen 518055, People's Republic of China; Kuijun Fu, State Key Laboratory of Metal Materials for Marine Equipment and Application, Iron \& Steel Research Institute of Ansteel Group Corporation, Anshan 114009, People's Republic of China. Contact e-mails: dzhao19phd@hit.edu.cn and lengxuesong@hit.edu.cn. the grain size and embrittlement of the microstructure in the HAZ (Ref 4-6). The toughness of the HAZ can be considerably improved by adding microalloying elements such as $\mathrm{Ti}, \mathrm{Nb}, \mathrm{V}$, $\mathrm{Mg}, \mathrm{Mn}$, and $\mathrm{Zr}$ in the high heat input welding of high strength low alloy steels. A-Rong et al. (Ref 7) found that the grain size was effectively refined, a large amount of acicular ferrite was formed in the weld metal, and the weld toughness could be improved with the addition of Ti contents of $0.028-0.038 \%$. Chen et al.(Ref 8) reported that steels with a high $\mathrm{Nb}$ content had an excellent weldability and proposed that the $\mathrm{C}$ content should be controlled at a lower level to use steels with a high $\mathrm{Nb}$ content efficiently. Zhang et al. (Ref 9) found that solid solution $\mathrm{Nb}$ can reduce the $\gamma-\alpha$ transition temperature, which promotes the formation of granular bainite. However, the addition of $\mathrm{Nb}$ can reduce the toughness of the CGHAZ, which has mainly been attributed to the microstructure of the CGHAZ changing from ferrite, pearlite, and a small amount of upper bainite to granular bainite and upper bainite. Moon et al. (Ref 10) reported that when adding $\mathrm{Nb}$ to Ti-containing HSLA steel, unstable $(\mathrm{Ti}, \mathrm{Nb})(\mathrm{N}, \mathrm{C})$ particles formed. $(\mathrm{Ti}, \mathrm{Nb})(\mathrm{N}, \mathrm{C})$ particle coarsening occurs more easily, which might weaken the pinning effect on austenite grain boundaries. Li et al. (Ref 11) found that the addition of $0.05 \% \mathrm{~V}$ to $\mathrm{C}-\mathrm{Mn}$ steel obtained a better toughness. Owing to the pinning effect of titanium-rich particles and precipitation strengthening derived from finely dispersed V-rich particles, Ti and V microalloying in steel is often applied to achieve grain size regulation (Ref 12). Additionally, some scholars have added $\mathrm{Mg}, \mathrm{Mn}, \mathrm{Zr}$ elements to high strength low alloy steels, as it may facilitate the formation of metal oxide and provide nucleation sites for the formation of acicular ferrite (Ref 13-15). TiNbV microalloyed steels are widely used for the construction of marine engineering equipment because of their high strength and appropriate toughness. The microstructure and toughness of the CGHAZ of TiNbV microalloyed steels by high heat input welding have 
been investigated, and important results have been obtained. However, the relationships among the toughness and the microconstituents and grain sizes of the coarse HAZ were not clear. Therefore, in this work, the phase constituent and grain size were accurately analyzed by using electron backscatter diffraction (EBSD). The relationship between the impact toughness and the microconstituents and grain sizes of the coarse HAZ for TiNbV microalloyed steels under different simulated thermal cycles was investigated. This work is of great significance to guide the development of high heat input welded steel.

\section{Materials and Methods}

The chemical composition and mechanical properties of the microalloyed steel were described by the Iron \& Steel Research Institute, Ansteel Group Corporation (Liaoning, China). The microalloyed steel was used in the investigation (chemical composition, wt.\%: C 0.079, Si 0.20, Mn 1.45, P 0.0036, S 0.0015 , Ni 0.16 , V 0.018 , Ti $0.016, \mathrm{~N} 0.0056)$. The mechanical properties of the microalloyed steel are shown in Table 1. The microstructure of the base metal is mainly composed of polygonal ferrite and pearlite as shown in Fig. 1. The steel plates were processed as thermal simulation samples with the dimensions of $10 \times 10 \times 105 \mathrm{~mm}$.

The thermal simulation experiments were performed by using a Gleeble 1500 thermal simulation test machine. The parameters of the simulated welding thermal cycles are shown in Table 2. The heat input for each experimental parameter was calculated by the Rykalin formula (Ref 16).

The thermal simulation samples were processed into metallographic samples with a size of $10 \times 10 \times 15 \mathrm{~mm}$ for EBSD analysis. The samples were ground with metallographic sandpaper and then polished with a $2.5 \mu \mathrm{m}$ diamond polishing solution. Then, the samples were electrolytically polished with $10 \%$ perchloric acid and 90\% glacial acetic acid. A Quanta 200FEG field emission scanning electron microscope equipped with a fully automatic EBSD analysis system was used to observe and analyze their microstructural features. The microconstituents of acicular ferrite, lath bainite, and pearlite were identified by comparing the EBSD grain maps and phase maps. The volume fraction of the microconstituents was calculated with Image-Pro Plus software. High-angle grain boundaries are defined as those having a misorientation greater than $15^{\circ}$, and low-angle grain boundaries are characterized as those with a misorientation between $2^{\circ}$ and $15^{\circ}$ (Ref 17). EBSD grain images and phase maps were taken in more than three areas of each sample.

Charpy V-notch impact tests were carried out at $-40{ }^{\circ} \mathrm{C}$ (JBDW-300D impact tester). According to the requirement of Chinese National Standard GB/T 229-2007 (Charpy pendulum impact test method) and after the thermal simulation treatment, the specimens were further machined into standard Charpy V-

Table 1 Mechanical properties of the steel plate

\begin{tabular}{cccc}
\hline $\boldsymbol{R}_{\mathrm{eH}}, \mathrm{MPa}$ & $\boldsymbol{R}_{\boldsymbol{m}}, \mathrm{MPa}$ & $\mathrm{A}, \boldsymbol{\%}$ & $\mathbf{- 4 0}{ }^{\circ} \mathrm{C}$ impact energy, J \\
\hline 435 & 522 & 28 & 310 \\
\hline
\end{tabular}

notch samples with dimensions of $10 \times 10 \times 55 \mathrm{~mm}$ for impact toughness measurements (Ref 18).

\section{Results and Discussion}

\subsection{Effect of Peak Temperature on the Microstructure of the Coarse HAZ}

Figure 2 shows the EBSD grain images and corresponding phase maps of the coarse HAZ by thermal cycling at different peak temperatures. In the phase maps, the red region and green region represent ferrite and cementite, respectively. The peak temperature reached $1250{ }^{\circ} \mathrm{C}$, and the microstructure of the simulated welded HAZ was composed of ferrite and pearlite (Fig. 2a). The microstructure was mainly composed of ferrite (Fig. 2b) as the peak temperature reached $1300{ }^{\circ} \mathrm{C}$. Simultaneously, the content of pearlite was reduced, and a small amount of bainite and acicular ferrite appeared. As the peak temperature increased to $1350{ }^{\circ} \mathrm{C}$, the content of bainite increased substantially, and some pearlite was generated again. At the same time, the grain size of the coarse HAZ increased (Fig. 2b). As the peak temperature further increased to $1400{ }^{\circ} \mathrm{C}$, the microstructure of the simulated $\mathrm{HAZ}$ was mainly composed of coarse ferrite and lath bainite (Fig. 2d).

Figure 3 shows the average grain size, microconstituent content, and relative grain boundary content of the simulated HAZ obtained by EBSD analysis of Fig. 2. Figure 3(a) shows that the average grain size increased slowly and then sharply. The grain size increased from $8.05 \mu \mathrm{m}$ to $17.13 \mu \mathrm{m}$ as the peak temperature increased from 1300 to $1400{ }^{\circ} \mathrm{C}$. As the peak temperature increased, the content of acicular ferrite first increased and then decreased, reaching a maximum of $13.21 \%$ at the peak temperature of $1300{ }^{\circ} \mathrm{C}$. As the peak temperature increased from 1250 to $1400{ }^{\circ} \mathrm{C}$, the content of bainite increased from 0.98 to $14.11 \%$, and the content of pearlite first increased and then decreased. From Fig. 3(b), it can be seen that the proportion of the high-angle grain boundaries first increased and then decreased with increasing peak temperatures. In addition, the relative content of the high-angle grain boundaries reached a maximum of $71.6 \%$ for the peak temperature of $1300{ }^{\circ} \mathrm{C}$. High-angle boundaries have been

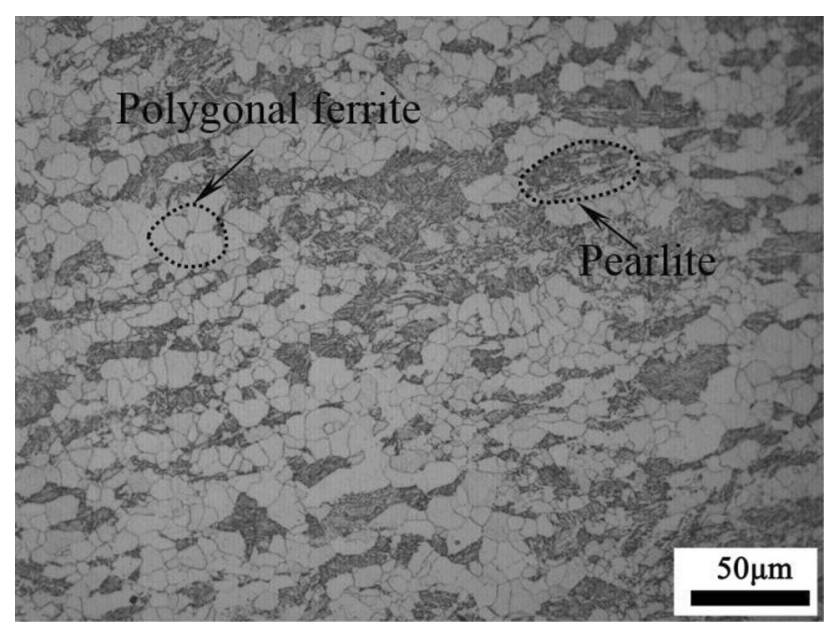

Fig. 1 The metallographic photo of the microalloyed steel used in the experiments 


\begin{tabular}{lcccc}
\hline & Peak temperature, $\boldsymbol{T}_{\mathbf{m a x}},{ }^{\circ} \mathbf{C}$ & Holding time at high temperature, $\boldsymbol{t}_{\boldsymbol{H}} / \mathbf{s}$ & $\boldsymbol{t}_{\mathbf{8} / \mathbf{5}} / \mathbf{s}$ & $\mathrm{Heat}$ input, $\mathbf{k J} / \mathbf{c m}$ \\
\hline 1 & 1250 & 0.2 & 200 & 50 \\
2 & 1300 & 0.2 & 200 & 50 \\
3 & 1350 & 0.2 & 200 & 50 \\
4 & 1400 & 0.2 & 200 & 100 \\
5 & 1300 & 1 & 200 & 160 \\
6 & 1300 & 10 & 200 & 200 \\
7 & 1300 & 1 & 300 & 70 \\
8 & 1300 & 1 & 300 & 140 \\
10 & 1300 & 1 & 400 & 220 \\
\hline
\end{tabular}

investigated and reported by many researchers to be able to arrest and cause deviation of brittle cracks during propagation, which is beneficial for maintaining a high toughness in the CGHAZ of low-carbon steels (Ref 19). It has been reported that acicular ferrite is a kind of high-angle grain boundary with a high dislocation density microstructure and a high strength and toughness (Ref 20,21). As the peak temperature increased, the content of acicular ferrite and high-angle grain boundaries showed similar trends.

\subsection{Effect of Holding Time at High Temperature on the Microstructure of the Coarse HAZ}

Figure 4 shows the EBSD grain images and corresponding phase maps of the coarse HAZ by thermal cycling for different holding times at high temperatures. In the phase maps, the red region and green region represent ferrite and cementite, respectively. For a holding time at a high temperature of $1 \mathrm{~s}$, the microstructure of the simulated welded HAZ was mainly composed of ferrite and a small amount of bainite and pearlite. Additionally, a large amount of acicular ferrite appeared. As the high-temperature holding time increased to $10 \mathrm{~s}$, the bainite content in the microstructure of the sample decreased considerably, and the structure was mainly composed of ferrite. In addition, the grain size of ferrite obviously increased, and the microstructure showed a relatively uniform distribution. As the holding time of high temperatures was extended to $20 \mathrm{~s}$, the microstructure of the simulated HAZ was mainly composed of ferrite, which was coarse and uniformly distributed.

Figure 5 shows the average grain sizes, microconstituents, and relative grain boundary contents of the coarse HAZ obtained by EBSD analysis in Fig. 2(b) and 4. Figure 5(a) shows that the grain size decreased slowly at first and then increased sharply with prolonged holding time at high temperatures. When the holding time at a high temperature increased from $10 \mathrm{~s}$ to $20 \mathrm{~s}$, the grain size increased from $7.71 \mu \mathrm{m}$ to $12.63 \mu \mathrm{m}$. The content of acicular ferrite first increased and then decreased sharply, reaching a maximum of $23.47 \%$ at a holding time of $1 \mathrm{~s}$. As the holding time at a high temperature increased, the bainite content remained unchanged. However, the contents of pearlite and ferrite first decreased and then increased. Figure 5(b) shows the relative content of the grain boundary ratio with increasing holding times at a high temperature. The proportion of the high-angle grain boundaries increased slightly as the holding time increased in the range of 0.2-1 s. Moreover, the relative content of high-angle grain boundaries reached a maximum of $80.5 \%$. for a holding time at a high temperature of $1 \mathrm{~s}$. The proportion of the high-angle grain boundaries decreased as the holding time increased in the range of 1-20 s.

\subsection{Effect of the Cooling Rate on the Microstructure of the Simulated HAZ}

Figure 6 shows the EBSD grain images and corresponding phase maps of the coarse HAZ for different cooling times $\left(t_{8 / 5}\right)$. In the phase maps, the red and green regions represent ferrite and cementite, respectively. The microstructure of the coarse HAZ was altered from bainite to ferrite and pearlite with prolonged $t_{8 / 5}$ time. When the $t_{8 / 5}$ time was $120 \mathrm{~s}$, the microstructure of the coarse HAZ was mainly composed of bainite and a small amount of ferrite (Fig. 6a). It was reported that a large amount of lath bainite may lead to crack propagation and reduce the toughness of the HAZ (Ref 22). When the $t_{8 / 5}$ time increased to $300 \mathrm{~s}$, the microstructure of the simulated HAZ was ferrite, and the grain size was coarse. Compared with a $t_{8 / 5}$ time of $120 \mathrm{~s}$, the content of bainite in the microstructure decreased, and a large number of acicular ferrites appeared (Fig. 6b) as the $t_{8 / 5}$ time increased to $300 \mathrm{~s}$. The acicular ferrites may effectively prevent crack propagation and improve the toughness of the HAZ (Ref 23). As the $t_{8 / 5}$ time was further extended to $400 \mathrm{~s}$, the microstructure of the simulated HAZ was mainly composed of mostly ferrite and a small amount of pearlite (Fig. 6c).

Figure 7 presents the average grain sizes, microconstituents, and relative grain boundary contents of the coarse HAZ obtained by EBSD analysis, as shown in Fig. 4(a) and 6. With increasing $t_{8 / 5}$ times, the grain size first decreased slightly and then increased sharply (Fig. 7a). When the $t_{8 / 5}$ time was $200 \mathrm{~s}$, the average grain size reached its minimum $(7.2 \mu \mathrm{m})$, and the average grain size increased from $7.2 \mu \mathrm{m}$ to $17.7 \mu \mathrm{m}$ with a further increase in $t_{8 / 5}$ time to $400 \mathrm{~s}$. The contents of acicular ferrite and the grain boundary first increased then decreased, reaching $23.47 \%$ with a $t_{8 / 5}$ time of $200 \mathrm{~s}$. The content of bainite and pearlite first decreased and then increased. When the $t_{8 / 5}$ time was $200 \mathrm{~s}$, the contents of bainite and pearlite were $3.67 \%$ and $3.27 \%$, respectively. The relative contents of the grain boundary ratio with increasing holding times at a high temperature are shown in Fig. 7(b). The proportion of the highangle grain boundaries increased sharply as the cooling time increased in the range of 120-200 s. The relative content of high-angle grain boundaries reached a maximum of $80.5 \%$ for a cooling time of $200 \mathrm{~s}$. As the cooling time further increased, the proportion of high-angle grain boundaries decreased sharply. 

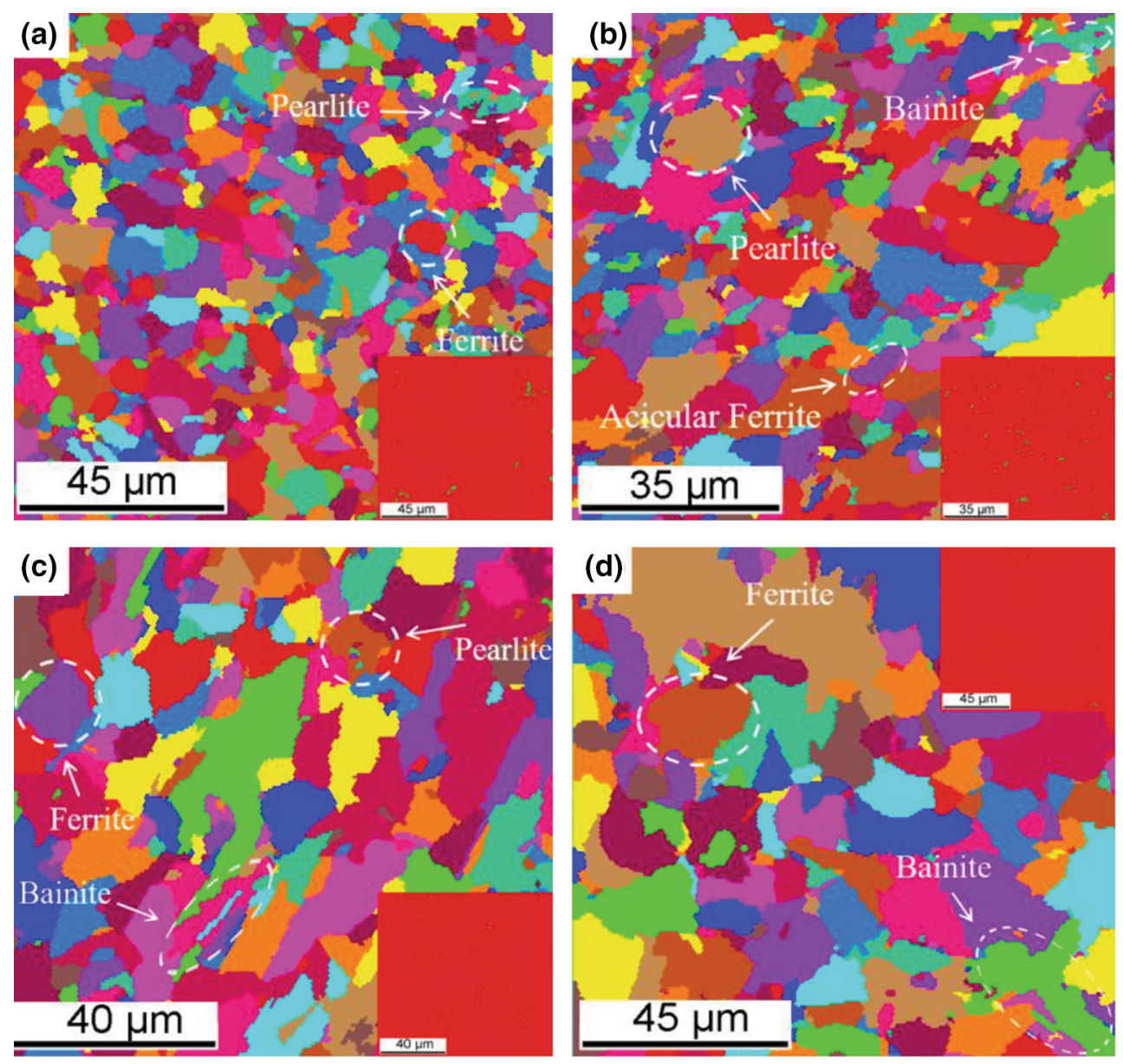

Fig. 2 The grain size and phase map of the coarse HAZ with different peak temperatures. (a) $T_{\max }=1250{ }^{\circ} \mathrm{C}$; (b) $T_{\max }=1300{ }^{\circ} \mathrm{C}$; (c) $T_{\max }$ $=1350{ }^{\circ} \mathrm{C}$; (d) $T_{\max }=1400{ }^{\circ} \mathrm{C}$
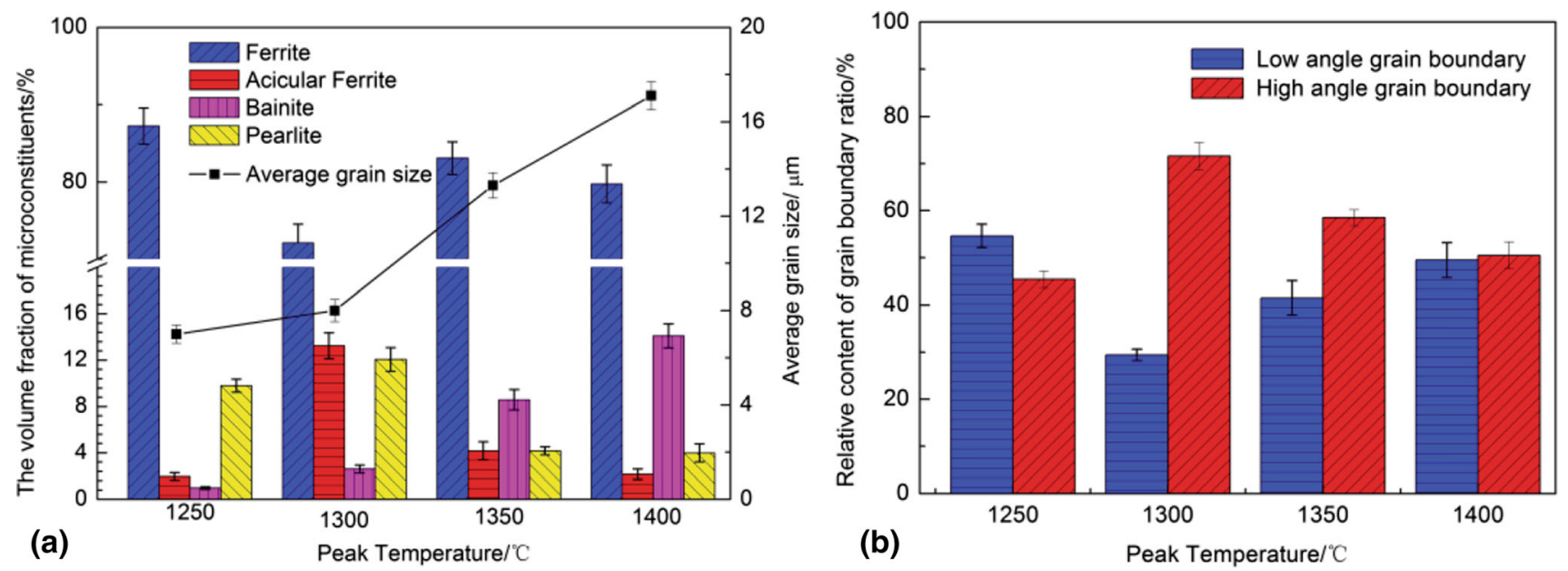

Fig. 3 Average grain size, microconstituents, and relative grain boundary content of the coarse HAZ at different peak temperatures

\subsection{Effect of Welding Thermal Cycle Parameters on the Impact Toughness of the Coarse HAZ}

Table 3 shows the experimental results of the Charpy Vnotch impact tests of the coarse HAZ with different simulated welding thermal cycle parameters. As the peak temperature increased, the impact toughness of the simulated welded HAZ first increased and then decreased. When the peak temperature was $1300{ }^{\circ} \mathrm{C}$, the impact energy of the simulated welded HAZ reached a maximum of $231 \mathrm{~J}$. As the peak temperature further increased to $1400{ }^{\circ} \mathrm{C}$, the impact energy decreased to $43 \mathrm{~J}$. With increasing holding time at high temperature, the toughness of the simulated welded HAZ first increased and then decreased. For the holding time at a high temperature of $1 \mathrm{~s}$, the impact 

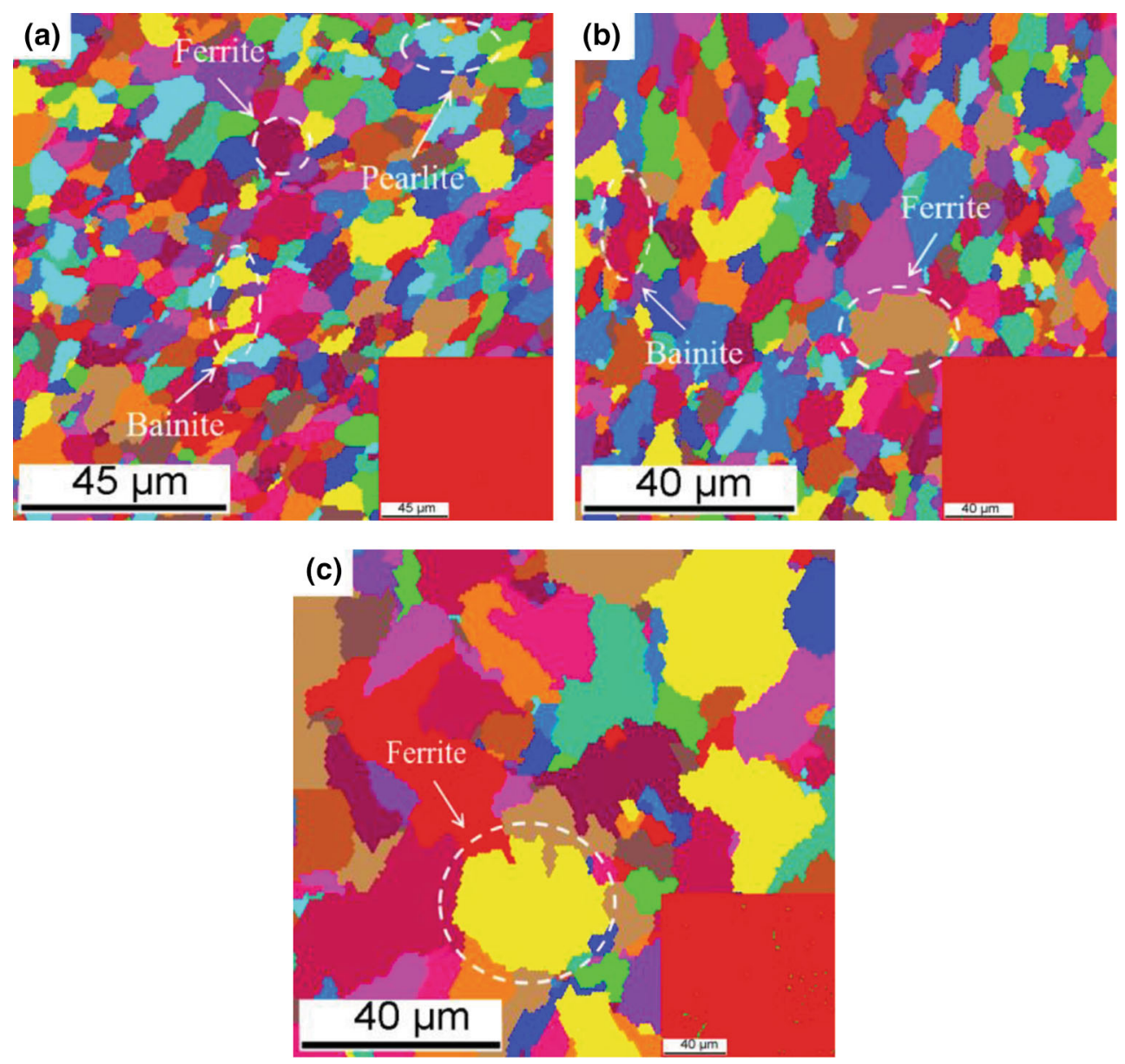

Fig. 4 The grain size and phase map of the coarse HAZ with different holding times at high temperature. (a) $t_{H}=1 \mathrm{~s}$; (b) $t_{H}=10 \mathrm{~s}$; (c) $t_{H}=20 \mathrm{~s}$
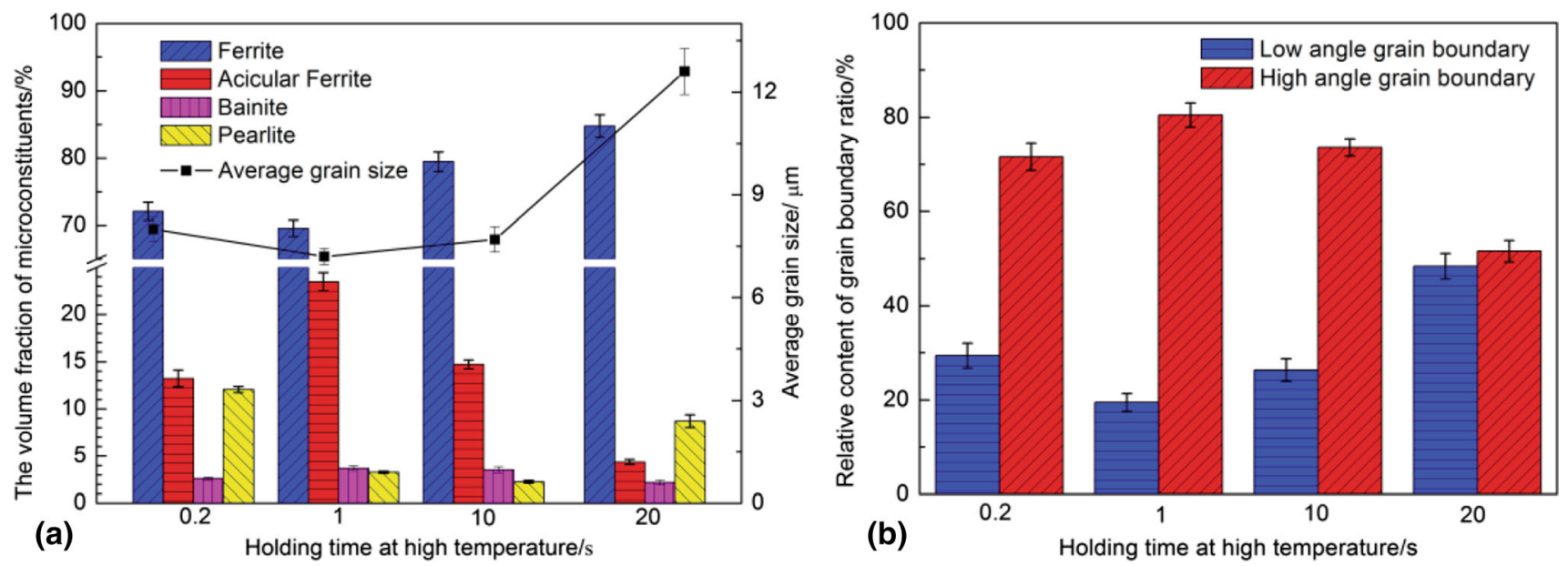

Fig. 5 Average grain size, microconstituents, and relative content of grain boundaries of simulated HAZ with different holding times at high temperature

energy of the simulated welding HAZ reached a maximum of $248 \mathrm{~J}$. The impact energy decreased to $118 \mathrm{~J}$ when the high temperature holding time increased to $20 \mathrm{~s}$. As the cooling time $\left(t_{8 / 5}\right)$ increased, the impact toughness of the simulated welding
HAZ first increased and then decreased. When the cooling time $\left(t_{8 / 5}\right)$ was $200 \mathrm{~s}$, the impact energy reached $249 \mathrm{~J}$. The impact energy decreased to $93.67 \mathrm{~J}$ when the cooling time $\left(t_{8 / 5}\right)$ further increased to $400 \mathrm{~s}$. 

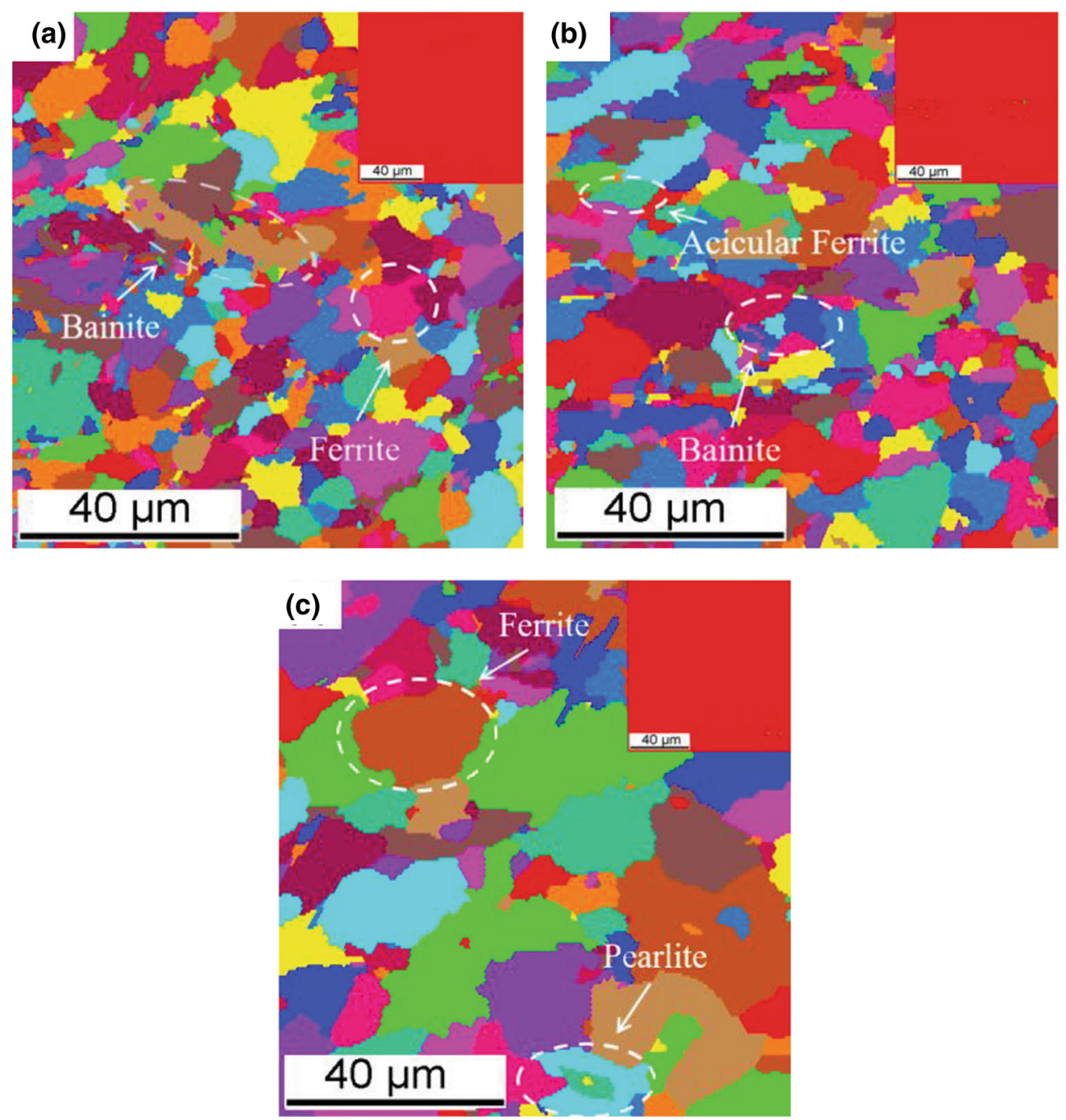

Fig. 6 Microstructure of the simulated HAZ with different cooling times. (a) $t_{8 / 5}=120 \mathrm{~s}$; (b) $t_{8 / 5}=300 \mathrm{~s}$; (c) $t_{8 / 5}=400 \mathrm{~s}$
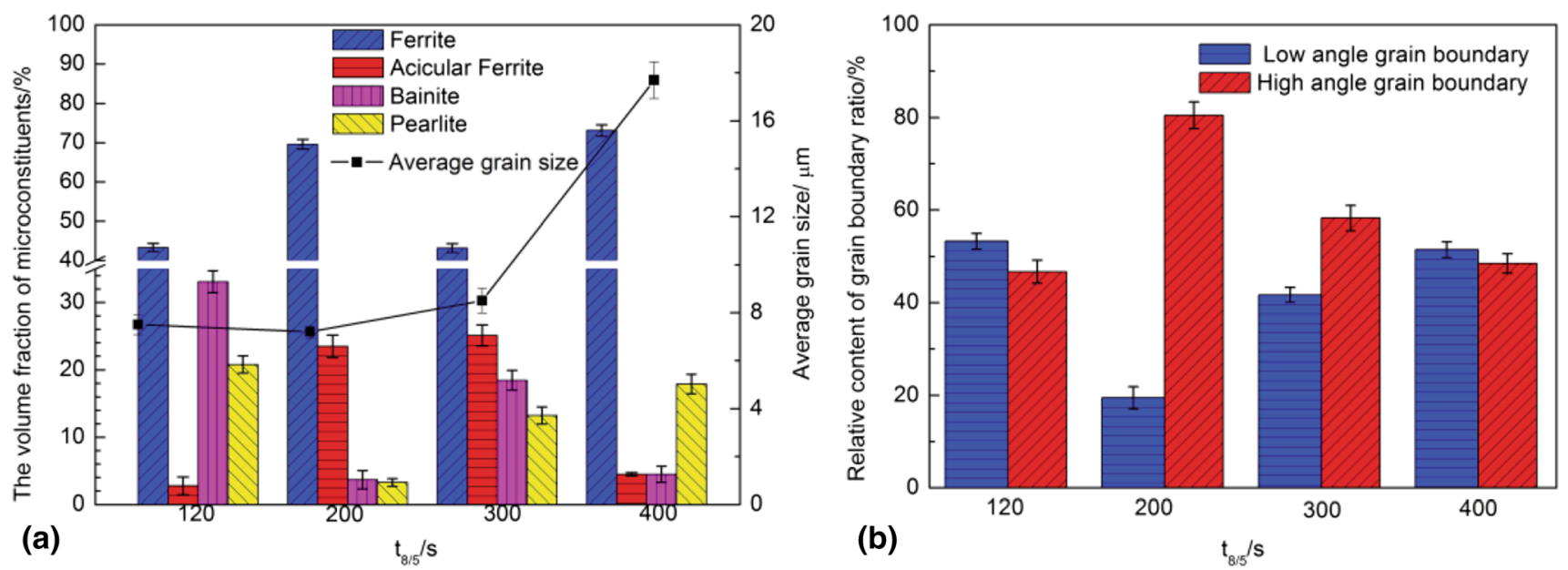

Fig. 7 Average grain size, microconstituents, and relative grain boundary content of the simulated HAZ with different cooling times

\subsection{Relationship Between the Bainite, Acicular Ferrite Content, Grain Size, and Impact Toughness}

Figure 8 shows the relationships among microconstituent contents (bainite, acicular ferrite), grain sizes, and impact toughness grades. In area I, the bainite content is less than $3.6 \%$, and the content of acicular ferrite is in the range of 1.96$23.47 \%$. With the low heat input $(30-70 \mathrm{~kJ} / \mathrm{cm})$, the impact toughness of the obtained CGHAZ joint is better. This is mainly 
Table 3 Impact energy with different welding thermal cycle parameters

\begin{tabular}{lrr}
\hline Welding thermal cycle parameters & & Charpy V-notch impact energy, J \\
\hline Peak temperature, $T_{\max } /{ }^{\circ} \mathrm{C}$ & 1250 & $224.31 \pm 3.29$ \\
& 1300 & $234.32 \pm 2.49$ \\
& 1350 & $73.33 \pm 2.35$ \\
Holding time at high temperature, $t_{H} / \mathrm{s}$ & 1400 & $41.12 \pm 1.63$ \\
& 0.2 & $234.33 \pm 2.67$ \\
& 1 & $247.15 \pm 2.94$ \\
$t_{8 / 5} / 5$ & 10 & $226.67 \pm 1.69$ \\
& 20 & $172.65 \pm 4.49$ \\
& 120 & $126.32 \pm 2.46$ \\
& 200 & $247.21 \pm 2.71$ \\
& 300 & $147.11 \pm 2.91$ \\
\end{tabular}

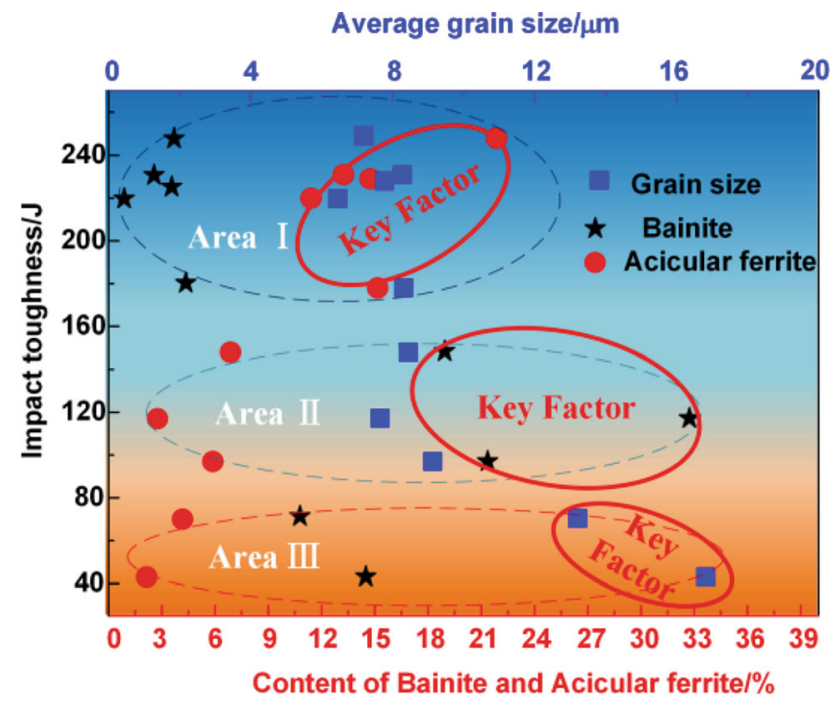

Fig. 8 Relationship between the content of bainite, acicular ferrite, grain size, and impact toughness

due to the sharp increase in the content of acicular ferrite, and the bainite content is lower. Here, the effect of the change in grain size on the material properties is almost negligible. The impact toughness of the CGHAZ is mainly controlled by acicular ferrite. The acicular ferrite structure presents a highly substructure nonequiaxed phase with high-density tangled dislocations (Ref 24, 25). Additionally, the acicular ferrite microstructure consisted of high-angle grain boundaries. In general, grain boundaries reveal the toughness of materials. When cracks meet high-angle grain boundaries, the crack torsion is not easy. However, the crack torsion effect for low grain boundaries readily occurs.

In area II, the bainite content increased sharply in the range of $18.47-33.08 \%$, and the impact toughness of the CGHAZ dropped sharply with the heat input in the range of $70-160 \mathrm{~kJ} /$ $\mathrm{cm}$. Moreover, the grain sizes and contents of acicular ferrite are not considerably altered, so the sharp drop in the impact toughness of CGHAZ is caused by the increase in the content of bainite. The carbides in the bainite are distributed between the ferrite laths, which can become the channel for crack propagation (Ref 26, 27). Therefore, a large amount of bainite will weaken the CGHAZ impact toughness.

In area III, the bainite content is $8.58-14.11 \%$, the grain size is larger (an increase from 13.3 to $17.7 \mu \mathrm{m}$ ), and the acicular ferrite content is lower. It was reported that $\mathrm{Nb}$ element addition can suppress the nucleation of ferrite at austenite grain boundaries and shifts $T s$ to lower temperatures. The $\mathrm{Nb}$ element facilitates the bainite transformation (Ref 28, 29). The CGHAZ impact toughness is poor with heat inputs larger than $160 \mathrm{~kJ} / \mathrm{cm}$. The combination of bainite content and grain size determines the CGHAZ impact toughness, but grain size plays a leading role in the CGHAZ impact toughness. Because of the coarse grain size and the small number of grain boundaries, the cracks easily propagate.

\subsection{Evolution of Second Phase Particles in CGHAZ}

Figure 9 shows TEM micrographs of the microstructure of the simulated CGHAZ in the experimental steel. It has demonstrated that the second phase particles and dislocations dispersed in CGHAZ. The lattice parameter of observed particles was calculated as $4.265 \AA$ from selected area diffraction (SAD) analysis (Fig. 10a). This value was between those of $\operatorname{TiN}(L=4.221 \AA)$ and $\operatorname{NbC}(L=4.47 \AA)$. This indicates that the complex type particles were $(\mathrm{Ti}, \mathrm{Nb})(\mathrm{C}, \mathrm{N})$ particles. Corresponding EDS analysis results are also confirmed in Fig. 10(b). It can be seen that when the peak temperature, holding time at a high temperature, and $t_{8 / 5}$ time was $1300{ }^{\circ} \mathrm{C}, 0.2 \mathrm{~s}, 200 \mathrm{~s}$, respectively (low heat input), a large number of small second phase particles are distributed in CGHAZ. The second particle size was mainly $50-100 \mathrm{~nm}$ as presented in Fig. 11(a). It was known that the number and size of second phase particles directly determine the degree of grain refinement. The smaller the particle size and the greater the quantity, and the uniform distribution of the second phase particle, which may effectively refine the microstructure of CGHAZ. With the increase in heat input, the number of second phase particles decreased, and the size gradually increased as illustrated in Fig. 9(b) and (c). This indicated that during the welding thermal cycle, the second phase particles are dissolved and coarsened. The increase in the average particle size may be attributed to two reasons: on the one hand, a large number of small-sized particles disappear due to dissolution during the welding thermal cycle; on the other hand, the remaining 

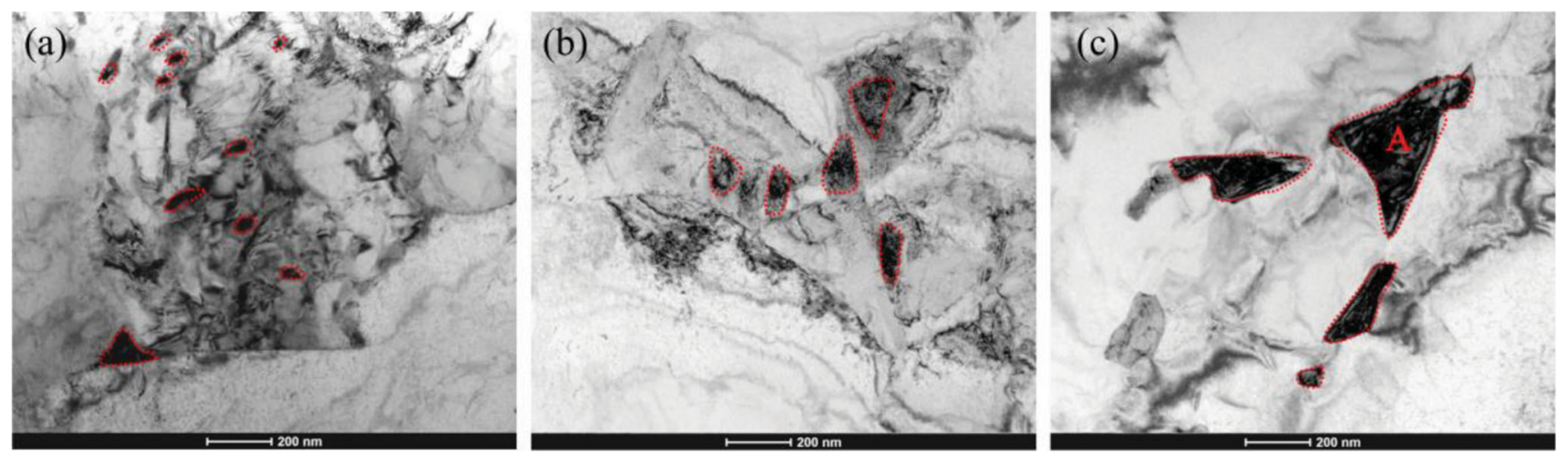

Fig. 9 TEM micrographs of particles in the matrix. (a) $T_{\max }=1300{ }^{\circ} \mathrm{C}, t_{H}=0.2 \mathrm{~s} t_{8 / 5}=200 \mathrm{~s}$; (b) $T_{\max }=1300{ }^{\circ} \mathrm{C}, t_{H}=1 \mathrm{~s} t_{8 / 5}=200 \mathrm{~s}$; (c) $T_{\max }=1300{ }^{\circ} \mathrm{C}, t_{H}=1 \mathrm{~s} t_{8 / 5}=400 \mathrm{~s}$
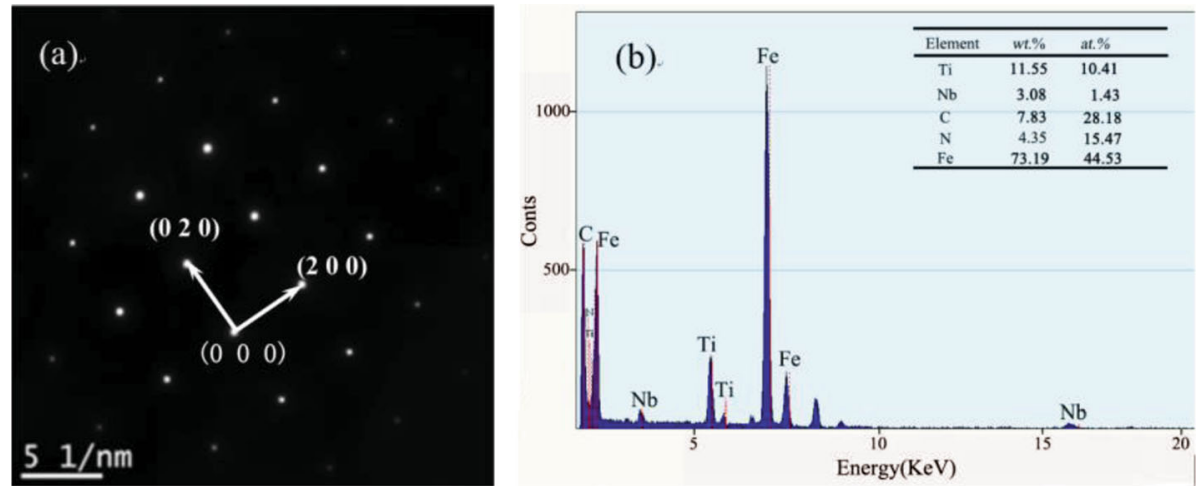

Fig. 10 Diffraction patterns and EDS of the precipitate particle of "A" in Fig. 9(c)
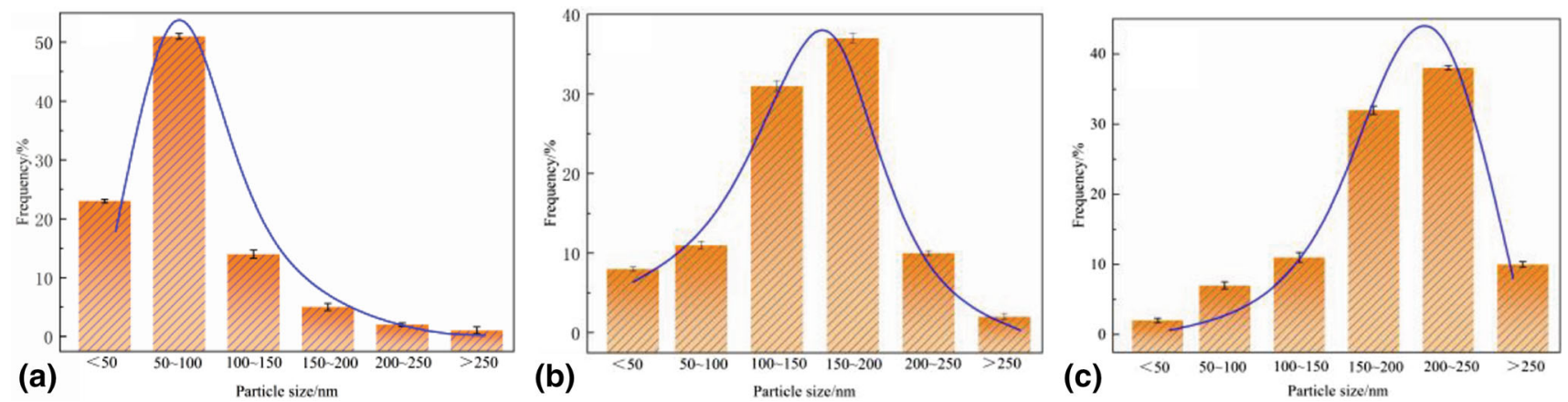

Fig. 11 The distribution of second particle size. (a) $T_{\max }=1300{ }^{\circ} \mathrm{C}, t_{H}=0.2 \mathrm{~s} t_{8 / 5}=200 \mathrm{~s}$; (b) $T_{\max }=1300{ }^{\circ} \mathrm{C}, t_{H}=1 \mathrm{~s} t_{8 / 5}=200 \mathrm{~s}$; (c) $T_{\max }$ $=1300{ }^{\circ} \mathrm{C}, t_{H}=1 \mathrm{~s} t_{8 / 5}=400 \mathrm{~s}$

particles grow up through the Ostwald mechanism. The coarsened second phase grain weakens the pinning of austenite, and the austenite grains will grow up sharply.

\section{Conclusions}

Based on the results above, the following conclusions can be summarized:

(1) The microstructure of the samples treated with various simulated welding thermal cycles consisted of ferrite, acicular ferrite, pearlite, and bainite. When the peak temperature, holding time at a high temperature, and $t_{8 / 5}$ time were $1250-1300{ }^{\circ} \mathrm{C}$, less than $1 \mathrm{~s}$, and $120-200 \mathrm{~s}$, respectively, the impact toughness of the CGHAZ was above $160 \mathrm{~J}$. In particular, the impact toughness of the CGHAZ reached a maximum of $231 \mathrm{~J}$ as the peak temperature, the holding time at high temperature, and the $t_{8 / 5}$ time was $1300{ }^{\circ} \mathrm{C}, 1 \mathrm{~s}$, and $200 \mathrm{~s}$, respectively.

(2) For low heat input welding $(30-70 \mathrm{~kJ} / \mathrm{cm})$, grain coarsening is not obvious, and the relative content of the high-angle grain boundaries increases. The impact toughness of the CGHAZ was better, which is mainly attributed to the increase in the high-angle grain boundaries of the acicular ferrite content. 
(3) The impact toughness and high-angle grain boundaries decreased, with increasing heat input welding degrees, which was attributed to the increasing bainite content. For welding with a high heat input $(>160 \mathrm{~kJ} / \mathrm{cm})$, the CGHAZ impact toughness was poor, which was directly related to the high bainite content and large grain size. The number of second phase particles decreased, and the size increased with the increase in heat input, which may weaken the pinning of austenite leading to the coarse grain size in CGHAZ.

\section{Acknowledgments}

This research is sponsored by the State Key Laboratory of Metal Material for Marine Equipment and Application (SKLMEAK201802), Iron \& Steel Research Institute, Ansteel Group Corporation.

\section{Conflicts of interest}

The authors declare no conflicts of interest.

\section{Open Access}

This article is licensed under a Creative Commons Attribution 4.0 International License, which permits use, sharing, adaptation, distribution and reproduction in any medium or format, as long as you give appropriate credit to the original author(s) and the source, provide a link to the Creative Commons licence, and indicate if changes were made. The images or other third party material in this article are included in the article's Creative Commons licence, unless indicated otherwise in a credit line to the material. If material is not included in the article's Creative Commons licence and your intended use is not permitted by statutory regulation or exceeds the permitted use, you will need to obtain permission directly from the copyright holder. To view a copy of this licence, visit http://creativecommons.org/licenses/by/4.0/.

\section{References}

1. A.R. Khan, Y. Shengfu, and H. Wang, Influence of Heat Input and Preheating on Microstructure and Mechanical Properties of Coarse Grain Heat-Affected Zone of Metal Arc Gas-Welded Pearlitic Rail Steel, J. Mater. Eng. Perform., 2019, 28(12), p 7676-7686

2. R. Cao, Z. Yang, J. Li, X. Liang, W. Lei, J. Zhang, and J. Chen, Effect of Peak Temperature on Microstructure and Mechanical Properties of Thermally Simulated Welding Heat-Affected Zones for 09MnNiDR Steel, J. Mater. Eng. Perform., 2020, 29(11), p 7063-7072

3. Y. Kitani, R. Ikeda, M. Ono, and K. Ikeuchi, Improvement of Weld Metal Toughness in High Heat Input Electro-Slag Welding of Low Carbon Steel, Weld. World, 2009, 53(3), p 57-63

4. W.W. Xu, Q.F. Wang, T. Pan, H. Su, and C.F. Yang, Effect of Welding Heat Input on Simulated HAZ Microstructure and Toughness of a V-N Microalloyed Steel, J. Iron Steel Res. Int., 2007, 14(5 SUPPL. 1), p 234-239

5. W. Sun, G. Wang, J. Zhang, D. Xia, and H. Sun, Microstructure Characterization of High-Heat-Input Welding Joint of HSLA Steel Plate for Oil Storage Construction, J. Mater. Sci. Technol., 2009, 25(6), p 857-860

6. L. Lan, C. Qiu, D. Zhao, X. Gao, and L. Du, Microstructural Characteristics and Toughness of the Simulated Coarse Grained Heat Affected Zone of High Strength Low Carbon Bainitic Steel, Mater. Sci. Eng. A, 2011, 529(1), p 192-200

7. L. Zhao, C. Pan, and Z.L. Tian, Influence of Ti on Weld Microstructure and Mechanical Properties in Large Heat Input Welding of High
Strength Low Alloy Steels, J. Iron Steel Res. Int., 2015, 22(5), p 431437

8. X.W. Chen, B. Liao, G.Y. Qiao, Y. Gu, X. Wang, and F.R. Xiao, Effect of $\mathrm{Nb}$ on Mechanical Properties of HAZ for High-Nb X80 Pipeline Steels, J. Iron Steel Res. Int., 2013, 20(12), p 53-60

9. Y.Q. Zhang, H.Q. Zhang, J.F. Li, and W.M. Liu, Effect of Heat Input on Microstructure and Toughness of Coarse Grain Heat Affected Zone in $\mathrm{Nb}$ Microalloyed HSLA Steels, J. Iron Steel Res. Int., 2009, 16(5), p p $73-80$

10. J. Moon, S. Kim, H. Jeong, J. Lee, and C. Lee, Influence of $\mathrm{Nb}$ Addition on the Particle Coarsening and Microstructure Evolution in a Ti-Containing Steel Weld HAZ, Mater. Sci. Eng. A, 2007, 454, p 648653

11. Y. Li, D.N. Crowther, M.J.W. Green, P.S. Mitchell, and T.N. Baker, Effect of Vanadium and Niobium on the Properties and Microstructure of the Intercritically Reheated Coarse Grained Heat Affected Zone in Low Carbon Microalloyed Steels, ISIJ Int., 2001, 41(1), p 46-55

12. J. Hu, L.X. Du, and J.J. Wang, Effect of V on Intragranular Ferrite Nucleation of High Ti Bearing Steel, Scr. Mater, 2013, 68(12), p 953956

13. L.Y. Xu, J. Yang, R.Z. Wang, Y.N. Wang, and W.L. Wang, Effect of $\mathrm{Mg}$ Content on the Microstructure and Toughness of Heat-Affected Zone of Steel Plate after High Heat Input Welding, Metall. Mater. Trans. A Phys. Metall. Mater. Sci., 2016, 47(7), p 3354-3364

14. F.Y. Song, M.H. Shi, P. Wang, F.X. Zhu, and R.D.K. Misra, Effect of Mn Content on Microstructure and Mechanical Properties of Weld Metal During High Heat Input Welding Processes, J. Mater. Eng. Perform., 2017, 26(6), p 2947-2953

15. M. Hao Shi, X. Guang Yuan, H. Jun Huang, and S. Zhang, Effect of Zr Addition on the Microstructure and Toughness of Coarse-Grained Heat-Affected Zone with High-Heat Input Welding Thermal Cycle in Low-Carbon Steel, J. Mater. Eng. Perform., 2017, 26(7), p 3160-3168

16. N.N. Rykalin, Calculation of Heat Processes in Welding, Office for Official Publications of the Europea, 1960, p 183-201

17. P. Zhou, B. Wang, L. Wang, Y. Hu, and L. Zhou, Effect of Welding Heat Input on Grain Boundary Evolution and Toughness Properties in CGHAZ of X90 Pipeline Steel, Mater. Sci. Eng. A., 2018, 722(3), p $112-121$

18. Metallic Materials - Charpy Pendulum Impact Test-Part 1: Test Method, ISO 148-1, Annual Book of ASTM Standards, ASTM, 2007, p 135-141

19. C. Wen, X. Deng, Y. Tian, Z. Wang, and R.D.K. Misra, Microstructural Evolution and Toughness of the Various HAZs in 1300-MPa-Grade Ultrahigh-Strength Structural Steel, J. Mater. Eng. Perform., 2019, 28(3), p 1301-1311

20. M. Fattahi, N. Nabhani, M.R. Vaezi, and E. Rahimi, Improvement of Impact Toughness of AWS E6010 Weld Metal by Adding TiO2 Nanoparticles to the Electrode Coating, Mater. Sci. Eng. A., 2011, 528(27), p 8031-8039

21. M. Fattahi, N. Nabhani, M. Hosseini, N. Arabian, and E. Rahimi, Effect of Ti-Containing Inclusions on the Nucleation of Acicular Ferrite and Mechanical Properties of Multipass Weld Metals, Micron, 2013, 45, p 107-114

22. W.L. Costin, O. Lavigne, and A. Kotousov, A Study on the Relationship between Microstructure and Mechanical Properties of Acicular Ferrite and Upper Bainite, Mater. Sci. Eng. A, 2016, 663, p 193-203

23. Y. Shao, C. Liu, Z. Yan, H. Li, and Y. Liu, Formation Mechanism and Control Methods of Acicular Ferrite in HSLA Steels: A Review, J. Mater. Sci. Technol., 2018, 34(5), p 737-744

24. Z. Xiong, S. Liu, X. Wang, C. Shang, X. Li, and R.D.K. Misra, The Contribution of Intragranular Acicular Ferrite Microstructural Constituent on Impact Toughness and Impeding Crack Initiation and Propagation in the Heat-Affected Zone (HAZ) of Low-Carbon Steels, Mater. Sci. Eng. A, 2015, 636, p 117-123

25. M. Diaz-Fuentes, A. Iza-Mendia, and I. Gutierrez, Analysis of Different Acicular Ferrite Microstructures in Low-Carbon Steels by Electron Backscattered Diffraction. Study of Their Toughness Behavior, Metall. Mater. Trans. A, 2003, 34(11), p 2505-2516

26. Y. Shi, and Z. Han, Effect of Weld Thermal Cycle on Microstructure and Fracture Toughness of Simulated Heat-Affected Zone for a 800 MPa Grade High Strength Low Alloy Steel, J. Mater. Process. Technol., 2008, 207(1-3), p 30-39 
27. A. Lambert-Perlade, A.F. Gourgues, and A. Pineau, Austenite to Bainite Phase Transformation in the Heat-Affected Zone of a High Strength Low Alloy Steel, Acta Mater, 2004, 52(8), p 2337-2348

28. Y. You, C. Shang, W. Nie, and S. Subramanian, Investigation on the Microstructure and Toughness of Coarse Grained Heat Affected Zone in X-100 Multi-Phase Pipeline Steel with High Nb Content, Mater. Sci. Eng. A, 2012, 558, p 692-701

29. Y.Q. Zhang, H.Q. Zhang, J.F. Li, and W.M. Liu, Effect of Heat Input on Microstructure and Toughness of Coarse Grain Heat Affected Zone in
Nb Microalloyed HSLA Steels, J. Iron Steel Res. Int., 2009, 16(5), p $73-80$

Publisher's Note Springer Nature remains neutral with regard to jurisdictional claims in published maps and institutional affiliations. 